This document is published in:

Combustion and Flame, Vol. 161, no 1, pp. 111-117

DOI: http://dx.doi.org/10.1016/j.combustflame.2013.07.013

(C) 2013 The Combustion Institute. Published by Elsevier Inc . 


\title{
The chemistry involved in the third explosion limit of $\mathrm{H}_{2}-\mathrm{O}_{2}$ mixtures
}

\author{
Antonio L. Sánchez ${ }^{\mathrm{a}, \mathrm{b}, *}$, Eduardo Fernández-Tarrazo a ${ }^{\text {, Forman A. Williams }}{ }^{\mathrm{b}}$ \\ a Dept. Ingeniería Térmica y de Fluidos, Universidad Carlos III de Madrid, Leganés 28911, Spain \\ ${ }^{\mathrm{b}}$ Dept. Mechanical and Aerospace Engineering, University of California San Diego, La Jolla, CA 92093-0411, USA
}

\begin{abstract}
A B S T R A C T
The third explosion limit of hydrogen oxidation in closed vessels has always been thought to be the result of the competition between homogeneous gas-phase reactions and diffusion of hydroperoxyl radicals to the walls, where they are destroyed. It has recently been observed that this species actually follows a chemical-kinetic steady state in this regime, with the consequence that its diffusive rate toward the catalytic walls becomes irrelevant. Here we show that the critical explosion conditions are determined instead by the fate of hydrogen peroxide, which emerges as the controlling reactant for the resulting gas-phase chemistry. A simple, accurate analytic expression for the third explosion limit follows from identification of the critical conditions for existence of weakly reactive, diffusion-reaction solutions, thereby providing the answer to a long-standing problem that in early work was characterized as being hopelessly difficult.
\end{abstract}

\section{Keywords:}

Hydrogen ignition

Explosion diagram

Third explosion limit

Reduced chemistry

Crossover temperature

Activation-energy asymptotics

\section{Introduction}

The ignitability of hydrogen-oxygen mixtures by elevated temperatures in closed chambers is known to possess a complex dependence on pressure $[1,2]$ that exhibits three different limits separating self-ignitable and non-self-ignitable states [3]. The existence of these so-called explosion limits, emerging as a consequence of the competition of chemical kinetics with species transport, was unveiled in early experiments of ignition of hydrogen-oxygen mixtures in spherical vessels coated with $\mathrm{KCl}$ (see, e.g., [4-6]), the gas-phase chemical kinetics competing with diffusive transport of species and their catalytic destruction at the wall surface. For a given mixture composition and a given vessel radius, identification of self-ignition conditions in a pressure-temperature plot produces a reverse $S$ curve. This is the classical explosion diagram shown in the first figure of Lewis and Von Elbe's book [3], which is reproduced here in Fig. 1.

Ignition in the lower peninsula of the diagram takes place as a branched-chain explosion controlled by the elementary reaction $\mathrm{H}+\mathrm{O}_{2} \rightarrow \mathrm{OH}+\mathrm{O}$ [7]. Consideration of rapid conversion of $\mathrm{O}$ and $\mathrm{OH}$ to $\mathrm{H}$ by the elementary reactions $\mathrm{H}_{2}+\mathrm{O} \rightarrow \mathrm{OH}+\mathrm{H}$ and $\mathrm{H}_{2}+\mathrm{OH} \rightarrow \mathrm{H}_{2} \mathrm{O}+\mathrm{H}$ leads to the overall reaction $3 \mathrm{H}_{2}+\mathrm{O}_{2} \rightarrow$ $2 \mathrm{H}_{2} \mathrm{O}+2 \mathrm{H}$ for radical production in this region. At low pressure, $\mathrm{H}$-atom production by this chain-branching reaction competes with radical diffusion to the walls, where radicals are destroyed

* Corresponding author at: Dept. Ingeniería Térmica y de Fluidos, Universidad Carlos III de Madrid, Leganés 28911, Spain. Fax: +34 916249430.

E-mail address: asanchez@ing.uc3m.es (A.L. Sánchez). by surface reactions. Since the molecular diffusivity is inversely proportional to the pressure, while the rate of radical production is proportional to the pressure squared, for sufficiently low pressures radical diffusion dominates, and a non-explosive behavior is found below the so-called first explosion limit. On the other hand, the upper bound of the lower peninsula is a purely chemical-kinetic limit that arises because of the competition of radical production through $3 \mathrm{H}_{2}+\mathrm{O}_{2} \rightarrow 2 \mathrm{H}_{2} \mathrm{O}+2 \mathrm{H}$ with the three-body radical termination step $\mathrm{H}+\mathrm{O}_{2}+\mathrm{M} \rightarrow \mathrm{HO}_{2}+\mathrm{M}$ [7], leading to the so-called second explosion limit.

For a given pressure, the associated temperature corresponding to the second limit is called the crossover temperature, a concept that has become central in studies of hydrogen combustion. For temperatures below crossover, i.e., for pressures above the second explosion limit, the branching path initiated by $\mathrm{H}+\mathrm{O}_{2} \rightarrow \mathrm{OH}+\mathrm{O}$ is precluded by the faster recombination reaction $\mathrm{H}+\mathrm{O}_{2}+$ $\mathrm{M} \rightarrow \mathrm{HO}_{2}+\mathrm{M}$, and the resulting chemical reaction proceeds at a much slower rate, so that ignition is neutralized by diffusive transport of species and subsequent destruction by surface reactions, leading to the appearance of a non-explosive region above the explosion peninsula. Even though the chemistry above the second explosion limit is extremely slow, with homogeneous ignition times being typically three orders of magnitude larger than those found above crossover, consideration of the reaction-diffusion balance indicates that, because of the increase of gas-phase chemical reaction rates with pressure and the accompanying reduction in species diffusivity, ignition may eventually take place provided that the pressure is increased to a sufficiently high value, thereby delineating a third explosion limit in the diagram. 


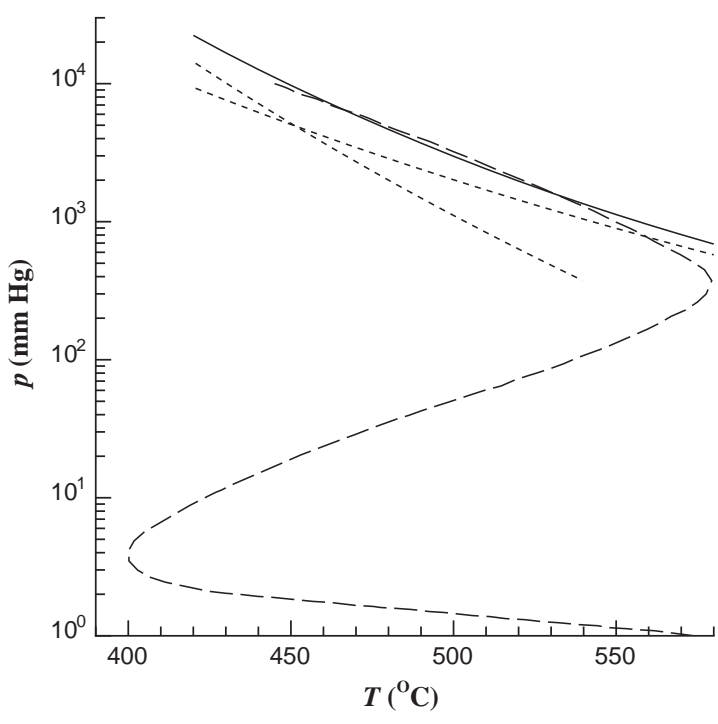

Fig. 1. The dashed curve corresponds to the experimental explosion limits of a stoichiometric hydrogen-oxygen mixture in a spherical $\mathrm{KCl}$-coated vessel of $7.4 \mathrm{~cm}$ diameter as shown by Lewis and Von Elbe (p. 8 of [3]), with the solid curve being the prediction of the third-explosion limit obtained by evaluation of (21) with $a=3.7 \mathrm{~cm}$ and $X_{\mathrm{H}_{2}}=0.66$ and the dotted lines being the corresponding lowpressure and high-pressure predictions obtained from (22) and (23).

Above the second explosion limit the radicals $\mathrm{H}, \mathrm{O}$, and $\mathrm{OH}$ are kept at low concentrations by the rapid reactions $\mathrm{H}+\mathrm{O}_{2}+$ $\mathrm{M} \rightarrow \mathrm{HO}_{2}+\mathrm{M}, \mathrm{H}_{2}+\mathrm{O} \rightarrow \mathrm{OH}+\mathrm{H}$, and $\mathrm{H}_{2}+\mathrm{OH} \rightarrow \mathrm{H}_{2} \mathrm{O}+\mathrm{H}$. Correspondingly, under those conditions, the ignition chemistry is dominated by reactions involving $\mathrm{HO}_{2}$ and $\mathrm{H}_{2} \mathrm{O}_{2}$ [3], with ignition occurring as a thermal explosion. The classical explanation for the third explosion limit relies on the competition of this slow chemistry with the diffusion of $\mathrm{HO}_{2}$ to the container walls $[8,9]$, where it is destroyed by catalytic reactions. This classical view, however, needs to be reconsidered in view of recent findings concerning ignition of hydrogen at temperatures below crossover [1012]. In particular, it has been shown [12] that after an initial stage of $\mathrm{HO}_{2}$ buildup, its consumption rate by $2 \mathrm{HO}_{2} \rightarrow \mathrm{H}_{2} \mathrm{O}_{2}+\mathrm{O}_{2}$ becomes dominant, keeping this species in steady state, with a local concentration that corresponds to the instantaneous productionconsumption balance. As a result, the critical conditions for the thermal explosion are determined instead by the competition of heat release and $\mathrm{H}_{2} \mathrm{O}_{2}$ production by gas-phase reactions with heat conduction and $\mathrm{H}_{2} \mathrm{O}_{2}$ diffusion towards the vessel walls, the diffusion of $\mathrm{HO}_{2}$ being negligible in the first approximation. We shall see below that the solution of the associated Frank-Kamenetskii problem for the thermal explosion in the spherical vessel yields a simple analytical expression for the third explosion limit that compares favorably with the upper curve of the experimental diagram of Fig. 1.

\section{The ignition chemistry at the third explosion limit}

To describe the interplay between $\mathrm{HO}_{2}$ and $\mathrm{H}_{2} \mathrm{O}_{2}$ leading to the thermal explosion at temperatures below crossover, three ratecontrolling elementary reactions need to be considered, namely $\mathrm{H}_{2} \mathrm{O}_{2}+\mathrm{M} \stackrel{1}{\rightarrow} 2 \mathrm{OH}+\mathrm{M}, 2 \mathrm{HO}_{2} \stackrel{2}{\rightarrow} \mathrm{H}_{2} \mathrm{O}_{2}+\mathrm{O}_{2}, \quad$ and $\quad \mathrm{HO}_{2}+\mathrm{H}_{2} \stackrel{3}{\rightarrow}$ $\mathrm{H}_{2} \mathrm{O}_{2}+\mathrm{H}$, whereas initiation reactions such as $\mathrm{H}_{2}+\mathrm{O}_{2} \rightarrow \mathrm{HO}_{2}+\mathrm{H}$, which are important in the early stages of time-dependent ignition processes [12], can be entirely neglected for determining critical explosion conditions. Additional consideration of the rapid removal of $\mathrm{OH}$ and $\mathrm{H}$ radicals through $\mathrm{OH}+\mathrm{H}_{2} \rightarrow \mathrm{H}_{2} \mathrm{O}+\mathrm{H}$ and $\mathrm{H}+\mathrm{O}_{2}+\mathrm{M} \rightarrow \mathrm{HO}_{2}+\mathrm{M}$ along with introduction of a steady-state assumption for $\mathrm{HO}_{2}$, motivated by its relatively rapid consumption through $2 \mathrm{HO}_{2} \stackrel{2}{\rightarrow} \mathrm{H}_{2} \mathrm{O}_{2}+\mathrm{O}_{2}$, readily leads to a simple two-step reduced description that suffices to quantify the ignition behavior accurately, as seen below.

Reduced chemistry of this general type for hydrogen combustion has been derived extensively in recent literature, not only for autoignition processes but also for flames. Besides the reduction on which the present analysis is based [12], recently employed in an investigation of diffusion-flame ignition in mixing layers [13] there now are three-step and four-step descriptions that apply to wide-ranging hydrogen applications [14]. The reductions to be applied in the present work are selected to be the simplest ones that can describe the third explosion limit with reasonable accuracy.

The development begins by noting that the two $\mathrm{OH}$ molecules created by the hydrogen-peroxide dissociation reaction $\mathrm{H}_{2} \mathrm{O}_{2}+\mathrm{M} \stackrel{1}{\rightarrow} 2 \mathrm{OH}+\mathrm{M}$ are rapidly destroyed by the occurrence of twice $\mathrm{OH}+\mathrm{H}_{2} \rightarrow \mathrm{H}_{2} \mathrm{O}+\mathrm{H}$ followed by twice $\mathrm{H}+\mathrm{O}_{2}+\mathrm{M} \rightarrow \mathrm{HO}_{2}+\mathrm{M}$ to eliminate the two $\mathrm{H}$ atoms produced, leading in a first stage to the overall reaction $\mathrm{H}_{2} \mathrm{O}_{2}+2 \mathrm{H}_{2}+2 \mathrm{O}_{2} \rightarrow 2 \mathrm{H}_{2} \mathrm{O}+2 \mathrm{HO}_{2}$ with a rate that is simply equal to that the elementary reaction $\mathrm{H}_{2} \mathrm{O}_{2}+\mathrm{M} \stackrel{1}{\rightarrow} 2 \mathrm{OH}+\mathrm{M}$. Under conditions of interest here, it has been shown [12] that ignition involves values of the hydroperoxyl concentration large enough for the elementary reaction $2 \mathrm{HO}_{2} \stackrel{2}{\rightarrow} \mathrm{H}_{2} \mathrm{O}_{2}+\mathrm{O}_{2}$ to proceed at a fast rate, such that the two $\mathrm{HO}_{2}$ molecules created by $\mathrm{H}_{2} \mathrm{O}_{2}+2 \mathrm{H}_{2}+2 \mathrm{O}_{2} \rightarrow 2 \mathrm{H}_{2} \mathrm{O}+2 \mathrm{HO}_{2}$ at a given location are immediately converted to $\mathrm{H}_{2} \mathrm{O}_{2}$ and $\mathrm{O}_{2}$ at that same location, with the consequence that the transport rate of $\mathrm{HO}_{2}$ becomes entirely negligible. The resulting $\mathrm{HO}_{2}$ concentration attains the local steady-state value

$\mathrm{C}_{\mathrm{HO}_{2}}=\left(k_{1} / k_{2}\right)^{1 / 2} C_{\mathrm{M}_{1}}^{1 / 2} C_{\mathrm{H}_{2} \mathrm{O}_{2}}^{1 / 2}$,

obtained by equating the rates of $\mathrm{HO}_{2}$ production and consumption, i.e., $2 \omega_{1}=2 \omega_{2}$. Here, $k_{j}$ is the rate coefficient of reaction $j$ and $C_{i}$ denotes the concentration of species $i$, with $C_{\mathrm{M}_{1}}$ representing the effective third-body concentration for the elementary reaction 1 , defined below in (12). Since $\mathrm{HO}_{2}$ recombination through $2 \mathrm{HO}_{2} \stackrel{2}{\rightarrow} \mathrm{H}_{2} \mathrm{O}_{2}+\mathrm{O}_{2}$ regenerates the hydrogen peroxide molecule that was originally used in initiating the reaction sequence, the final overall step associated with the steady state of $\mathrm{HO}_{2}$,

$2 \mathrm{H}_{2}+\mathrm{O}_{2} \rightarrow 2 \mathrm{H}_{2} \mathrm{O}$,

derived by addition of $\mathrm{H}_{2} \mathrm{O}_{2}+2 \mathrm{H}_{2}+2 \mathrm{O}_{2} \rightarrow 2 \mathrm{H}_{2} \mathrm{O}+2 \mathrm{HO}_{2}$ and $2 \mathrm{HO}_{2} \stackrel{2}{\rightarrow} \mathrm{H}_{2} \mathrm{O}_{2}+\mathrm{O}_{2}$, neither produces nor destroys $\mathrm{H}_{2} \mathrm{O}_{2}$, although its rate is proportional to the concentration of this species according to

$\omega_{\mathrm{I}}=\omega_{1}=k_{1} C_{\mathrm{M}_{1}} C_{\mathrm{H}_{2} \mathrm{O}_{2}}$

It is of interest that the fast elementary reaction $2 \mathrm{HO}_{2} \stackrel{2}{\rightarrow} \mathrm{H}_{2} \mathrm{O}_{2}+\mathrm{O}_{2}$ in the gas phase, responsible for the $\mathrm{HO}_{2}$ steady state, was not present in the early theoretical analyses [8,9], leading these investigators to conclude erroneously that $\mathrm{HO}_{2}$ transport was essential for defining the explosion conditions at the third limit. It may be noted that this same error continues to be made today [15].

Since the preceding path neither produces nor destroys $\mathrm{H}_{2} \mathrm{O}_{2}$, production of hydrogen peroxide relies on the elementary reaction $\mathrm{HO}_{2}+\mathrm{H}_{2} \stackrel{3}{\rightarrow} \mathrm{H}_{2} \mathrm{O}_{2}+\mathrm{H}$. This does not alter, however, the concentration of $\mathrm{HO}_{2}$, because subsequent removal of the $\mathrm{H}$ atom through $\mathrm{H}+\mathrm{O}_{2}+\mathrm{M} \rightarrow \mathrm{HO}_{2}+\mathrm{M}$ leads by straightforward addition of these two elementary steps to the overall reaction

$\mathrm{H}_{2}+\mathrm{O}_{2} \rightarrow \mathrm{H}_{2} \mathrm{O}_{2}$

with corresponding rate $\omega_{\text {II }}=\omega_{3}$. This last step is autocatalytic, in that it produces $\mathrm{H}_{2} \mathrm{O}_{2}$ with a rate that is proportional to the square root of its concentration, as can be seen by using the steady-state expression for $\mathrm{HO}_{2}$, given in (1), to write

$\omega_{\text {II }}=\omega_{3}=k_{3}\left(k_{1} / k_{2}\right)^{1 / 2} C_{\mathrm{M}_{1}}^{1 / 2} C_{\mathrm{H}_{2}} C_{\mathrm{H}_{2} \mathrm{O}_{2}}^{1 / 2}$. 
It is noteworthy that the autocatalytic character of $\mathrm{H}_{2} \mathrm{O}_{2}$ also arises in reduced autoignition chemistry of hydrocarbons [16,17].

The two overall steps I and II, together with their associated rates, given, respectively, in (2) and (3), provide the chemistry description needed to study ignition at the third explosion limit, which takes place as a thermal explosion because of the strong temperature sensitivity of both reactions. Both steps have distinct necessary roles in the explosion development. Thus, because the heat of reaction associated with I is about four times larger than that of II, the enthalpy of formation of $\mathrm{H}_{2} \mathrm{O}$ being about twice that of $\mathrm{H}_{2} \mathrm{O}_{2}$, heat release relies predominantly on the first global step, whereas the second step contributes to the ignition process by creating in an autocatalytic fashion the $\mathrm{H}_{2} \mathrm{O}_{2}$ needed to enable both reactions to proceed, as dictated by (2) and (3). It seems remarkable that this relatively simple chemistry has not been identified previously.

\section{Frank-Kamenetskii thermal-explosion analysis}

As explained in [18], critical conditions for ignition of reactive mixtures in vessels can be identified by considering timedependent reaction histories, the approach originally postulated by Semenov and often adopted subsequently, for instance, in [19], or by investigating the existence of steady, weakly reactive solutions, as was done by Frank-Kamenetskii in his theory of thermal explosions. In analyzing the explosion problem of Lewis and Von Elbe [3], including a stoichiometric mixture of hydrogen and oxygen confined in a closed spherical vessel of radius $a$ with a catalytic wall, we choose to adopt here the Frank-Kamenetskii approach, using in the formulation the two-step chemistry presented above. The associated spherically-symmetric temperature and $\mathrm{H}_{2} \mathrm{O}_{2}$ profiles can be determined by neglecting variations of density and transport properties (because of the nearly isothermal, nearly uniform conditions), along with reactant consumption and heat release by $\mathrm{H}_{2} \mathrm{O}_{2}$ formation, to write the reduced conservation equations

$\frac{\lambda}{r^{2}} \frac{\mathrm{d}}{\mathrm{d} r}\left(r^{2} \frac{\mathrm{d} T}{\mathrm{~d} r}\right)=2 h_{\mathrm{H}_{2} \mathrm{O}} \omega_{\mathrm{I}}$

$\frac{D_{\mathrm{H}_{2} \mathrm{O}_{2}}}{r^{2}} \frac{\mathrm{d}}{\mathrm{d} r}\left(r^{2} \frac{\mathrm{d} C_{\mathrm{H}_{2} \mathrm{O}_{2}}}{\mathrm{~d} r}\right)=-\omega_{\text {II }}$.

A Fickian description has been adopted in writing the diffusive flux in (5), a result that follows from solving exactly the multicomponent transport equation [20] for the diffusion velocity of hydrogen peroxide into a uniform binary mixture. The resulting effective diffusivity

$D_{\mathrm{H}_{2} \mathrm{O}_{2}}=\left(\frac{X_{\mathrm{H}_{2}}}{D_{\mathrm{H}_{2} \mathrm{O}_{2}-\mathrm{H}_{2}}}+\frac{\left(1-X_{\mathrm{H}_{2}}\right)}{D_{\mathrm{H}_{2} \mathrm{O}_{2}-\mathrm{O}_{2}}}\right)^{-1}$

is a function of the binary diffusion coefficients $D_{\mathrm{H}_{2} \mathrm{O}_{2}-\mathrm{H}_{2}}$ and $D_{\mathrm{H}_{2} \mathrm{O}_{2}-\mathrm{O}_{2}}$, with $\mathrm{X}_{\mathrm{H}_{2}}$ representing the mole fraction of $\mathrm{H}_{2}$. The above equations must be integrated with the boundedness conditions $\mathrm{d} T / \mathrm{d} r=\mathrm{d}_{\mathrm{H}_{2} \mathrm{O}_{2}} / \mathrm{d} r=0$ at the center $r=0$ and the boundary conditions $T-T_{o}=C_{\mathrm{H}_{2} \mathrm{O}_{2}}=0$ at $r=a$, the latter imposing a fixed temperature $T_{o}$ at the wall (maintained with a thermostat in experiments), where it is assumed that hydrogen peroxide is rapidly destroyed by the fast surface reaction $\mathrm{H}_{2} \mathrm{O}_{2} \rightarrow \mathrm{H}_{2}+\mathrm{O}_{2}$. In the formulation, $h_{\mathrm{H}_{2} \mathrm{O}}=-241,845 \mathrm{~J} / \mathrm{mol}$ is the enthalpy of formation of water vapor and $\lambda$ is the thermal conductivity of the reactive mixture.

To write the ignition problem in dimensionless form, we note that the temperature sensitivities of the elementary reactions $\mathrm{H}_{2} \mathrm{O}_{2}+\mathrm{M} \stackrel{1}{\rightarrow} 2 \mathrm{OH}+\mathrm{M}$ and $\mathrm{HO}_{2}+\mathrm{H}_{2} \stackrel{3}{\rightarrow} \mathrm{H}_{2} \mathrm{O}_{2}+\mathrm{H}$ are very large, with resulting activation temperatures for the overall reactions I and II, associated with the coefficients $k_{1}$ and $k_{3}\left(k_{1} / k_{2}\right)^{1 / 2}$, that can be seen to be almost identical, as shown in the evaluations below. Consequently, differences between the two overall activation temperatures can be neglected in the Frank-Kamenetskii linearization of the rates, involving a dimensionless temperature increment from the boundary value,

$\theta=\beta \frac{T-T_{o}}{T_{o}}$,

along with the same dimensionless activation energy $\beta$ for both reactions, defined below in (18). An order-of-magnitude analysis of (4) can be used to deduce the characteristic hydrogen peroxide concentration

$C_{\mathrm{H}_{2} \mathrm{O}_{2 c}}=\frac{\lambda T_{o} / \beta}{\left(-2 h_{\left.\mathrm{H}_{2} \mathrm{O}\right)} k_{1} C_{\mathrm{M}_{1}} a^{2}\right.}$

required to increase the temperature by an amount of the order of the Frank-Kamenetskii increment $T_{o} / \beta$, associated with ignition. Introducing the dimensionless temperature $\theta$ and accompanying $\mathrm{H}_{2} \mathrm{O}_{2}$ concentration $\varphi=C_{\mathrm{H}_{2} \mathrm{O}_{2}} / C_{\mathrm{H}_{2} \mathrm{O}_{2 c}}$, along with the dimensionless radial coordinate $\eta=r / a$, reduces the problem to that of integrating

$\left.\begin{array}{ll}\frac{1}{\eta^{2}} \frac{\mathrm{d}}{\mathrm{d} \eta}\left(\eta^{2} \frac{\mathrm{d} \theta}{\mathrm{d} \eta}\right)=-\varphi e^{\theta} ; & \theta(1)=\frac{\mathrm{d} \theta}{\mathrm{d} \eta}(0)=0 \\ \frac{1}{\eta^{2}} \frac{\mathrm{d}}{\mathrm{d} \eta}\left(\eta^{2} \frac{\mathrm{d} \varphi}{\mathrm{d} \eta}\right)=-D a \varphi^{1 / 2} e^{\theta} ; & \varphi(1)=\frac{\mathrm{d} \varphi}{\mathrm{d} \eta}(0)=0\end{array}\right\}$.

As can be seen, the only controlling parameter is the Damköhler number

$D a=k_{3}\left(k_{1} / k_{2}\right)^{1 / 2} \frac{C_{\mathrm{M}_{1}}^{1 / 2} C_{\mathrm{H}_{2}}}{C_{\mathrm{H}_{2} \mathrm{O}_{2 c}}^{1 / 2}}\left(a^{2} / D_{\mathrm{H}_{2} \mathrm{O}_{2}}\right)$

defined as the ratio of the diffusion time across the vessel, $a^{2} / D_{\mathrm{H}_{2} \mathrm{O}_{2}}$, to the characteristic chemical time required to increase the $\mathrm{H}_{2} \mathrm{O}_{2}$ concentration to a value of the order of $\mathrm{C}_{\mathrm{H}_{2} \mathrm{O}_{2}}$, given by $\left[k_{3}\left(k_{1} / k_{2}\right)^{1 / 2} C_{\mathrm{M}_{1}}^{1 / 2} C_{\mathrm{H}_{2}} C_{\mathrm{H}_{2} \mathrm{O}_{\mathrm{c}}}^{-1 / 2}\right]^{-1}$.

Numerical shooting was employed to determine nontrivial solutions of (9) for a given value of $D a$. The resulting variations with $D a$ of the maximum values of $\theta$ and $\varphi$, reached at the container center, are shown in Fig. 2. As occurs in the classical Frank-Kamenetskii analysis of thermal explosions for one-step Arrhenius kinetics, two different nontrivial solutions exist for any given value of $D a$ smaller than a critical value, which was found to be $D a_{c}=10.25$, and no weakly reacting solution exists for $D a>D a_{c}$, indicating that this critical value identifies ignition conditions.

Using the definitions (8) and (10) together with the value $D a_{c}=10.25$, obtained numerically, yields

$a=\left[\frac{10.25 D_{\mathrm{H}_{2} \mathrm{O}_{2}}\left(\lambda T_{o} k_{2}\right)^{1 / 2}}{k_{1} k_{3} C_{\mathrm{M}_{1}} C_{\mathrm{H}_{2}}\left(-2 \beta h_{\mathrm{H}_{2} \mathrm{O}}\right)^{1 / 2}}\right]^{1 / 3}$

for the critical conditions corresponding to the third explosion limit. The equation has been rearranged to give explicitly the critical value of the vessel radius for given values of the temperature, pressure, and $\mathrm{H}_{2}$ concentration. It can also be employed to determine implicitly the critical value of any of the last three quantities in terms of the other two and the vessel radius. The evaluation requires knowledge of the rate constants for reactions 1-3, as well as the transport coefficients $\lambda$ and $D_{\mathrm{H}_{2} \mathrm{O}_{2}}$, for which associated expressions are given below.

\section{Reaction-rate and transport parameters for the evaluation of the third explosion limit}

The rate coefficient for the hydrogen-peroxide dissociation reaction $\mathrm{H}_{2} \mathrm{O}_{2}+\mathrm{M} \stackrel{1}{\rightarrow} 2 \mathrm{OH}+\mathrm{M}$ can be taken from the recent evaluation of Troe [21], with $\mathrm{O}_{2}$ used as bath gas in computing the lowpressure coefficient $k_{0}$, as is appropriate to enable a more direct 


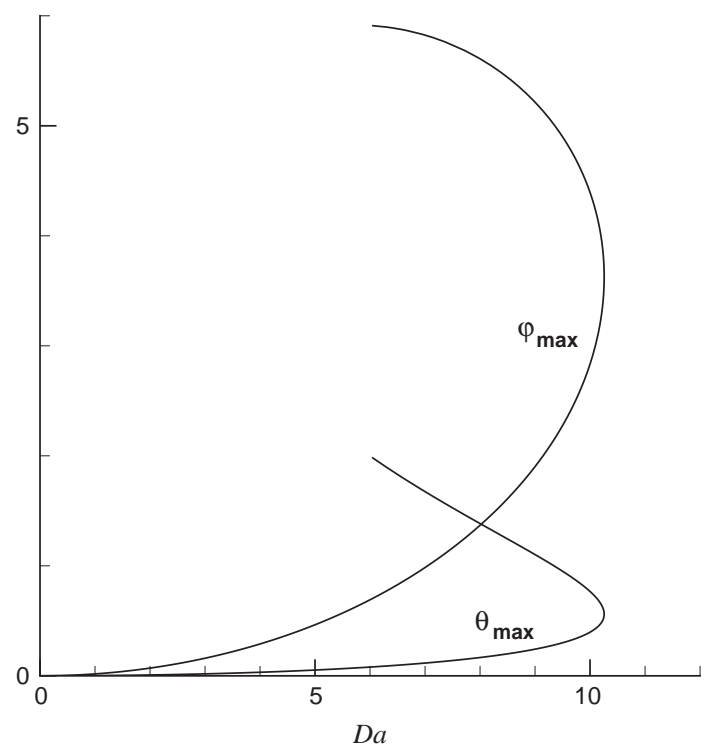

Fig. 2. The variation with $D a$ of the peak values of $\theta$ and $\varphi$.

comparison with the experimental results of the explosion diagram in [3]. Correspondingly, the constant value $F_{c}=0.42$ suggested for $\mathrm{O}_{2}$ in [21] is adopted below when evaluating the Troe fall-off factor appearing in (13) below. In the absence of a specific recommendation for the chaperon efficiency of $\mathrm{H}_{2}$ relative to $\mathrm{O}_{2}$, a value equal to 2.5 is assumed, since that value has often been used for other three-body steps, so that the effective third-body concentration for this reaction in a $\mathrm{H}_{2}-\mathrm{O}_{2}$ mixture can be expressed as

$C_{\mathrm{M}_{1}}=\left(1+1.5 X_{\mathrm{H}_{2}}\right) p /\left(R^{0} T_{0}\right)$

in terms of the pressure $p$, temperature $T_{o}$, and hydrogen mole fraction $X_{\mathrm{H}_{2}}$, with $R^{o}=8.314 \mathrm{~J} /(\mathrm{mol} \mathrm{K})$ representing the universal gas constant. The resulting rate constant can be written in the form

$k_{1}=\frac{0.42^{\left\{1+[0.814 \log x]^{2}\right\}^{-1}}}{1+x} k_{0}$

with the low-pressure coefficient

$k_{0}=2.89 \times 10^{24} T_{o}^{-2.3} \exp \left(-24,534 / T_{o}\right)$

expressed in $\mathrm{cm}^{3} \mathrm{~mol}^{-1} \mathrm{~s}^{-1}$ and the dimensionless coefficient ratio $x=k_{0} C_{\mathrm{M}_{1}} / k_{\infty}$ given by [21]

$x=7.76 \times 10^{10} T_{o}^{-4.2} p\left(1+1.5 X_{\mathrm{H}_{2}}\right)$

if $T$ is in $\mathrm{K}$ and $p$ is in atm, respectively. Straightforward evaluation of (13) indicates that fall-off effects are quite significant for the conditions pertaining to the explosion diagram of [3], so that, for instance, with $X_{\mathrm{H}_{2}}=0.66$, the value $k_{1} / k_{0}=0.541$ is obtained from (13) for $T_{o}=800 \mathrm{~K}$ and $p=1 \mathrm{~atm}$, further decreasing to $k_{1} / k_{0}=0.159$ for $T_{o}=700 \mathrm{~K}$ and $p=10 \mathrm{~atm}$.

As for the rate coefficient of the other two relevant elementary reactions $2 \mathrm{HO}_{2} \stackrel{2}{\rightarrow} \mathrm{H}_{2} \mathrm{O}_{2}+\mathrm{O}_{2}$ and $\mathrm{HO}_{2}+\mathrm{H}_{2} \stackrel{3}{\rightarrow} \mathrm{H}_{2} \mathrm{O}_{2}+\mathrm{H}$, the former has been known for some time to reach a minimum at a temperature of the order of $T=800 \mathrm{~K}[22,23]$, a behavior that can be reproduced by consideration of a bi-Arrhenius rate law, the more recent expression [23]

$k_{2}=1.03 \times 10^{14} \exp \left(-5556 / T_{o}\right)+1.94 \times 10^{11} \exp \left(709 / T_{o}\right)$

being used below for evaluating this constant. Since (16) exhibits a minimum at the conditions of interest, the temperature variation of $k_{2}$ does not contribute significantly to the self-acceleration of the chemical reaction during the thermal explosion, so that this coefficient is correspondingly treated as a constant in the ignition analysis.

Of the three rate constants appearing in (11), that of reaction $\mathrm{HO}_{2}+\mathrm{H}_{2} \stackrel{3}{\rightarrow} \mathrm{H}_{2} \mathrm{O}_{2}+\mathrm{H}$ suffers from the largest degree of uncertainty. There are just a few experimental data available at temperatures above $500 \mathrm{~K}$, and they correspond to the reverse reaction $\mathrm{H}_{2} \mathrm{O}_{2}+\mathrm{H} \rightarrow \mathrm{HO}_{2}+\mathrm{H}_{2}$, its rate coefficient being deduced from indirect observations involving a number of estimated quantities, including the relative rate of the alternative channel $\mathrm{H}_{2} \mathrm{O}_{2}+$ $\mathrm{H} \rightarrow \mathrm{H}_{2} \mathrm{O}+\mathrm{OH}$ (see, e.g., [24]). To derive expressions for $k_{3}$, different authors use the limited available experimental information in different ways, leading to predictions that differ by as much as a factor of 3, with the largest value being that used in [25] and the smallest values being those proposed in $[26,27]$. In the following, we shall employ the intermediate value

$k_{3}=2.40 \times 10^{11} T_{o}^{0.56} \exp \left(-12,117 / T_{o}\right)$,

computed with use of the equilibrium constant from the expression proposed for the coefficient of the reverse step in [28]. The sensitivity of the results to the specific value selected for this rate coefficient is to be discussed below, along with the influence of the chaperon efficiency of $\mathrm{H}_{2}$ in $\mathrm{H}_{2} \mathrm{O}_{2}+\mathrm{M} \stackrel{1}{\rightarrow} 2 \mathrm{OH}+\mathrm{M}$. Units of (16) and (17) are those of (14), with $T_{o}$ expressed in $\mathrm{K}$ in all three equations.

As previously mentioned, the temperature sensitivities for the two global rates $\omega_{\text {I }}$ and $\omega_{\text {II }}$ are very large because of the large activation temperatures present in (14) and (17). The resulting effective activation temperatures for the two overall coefficients $k_{1}$ and $k_{3}\left(k_{1} / k_{2}\right)^{1 / 2}$ emerging in (2) and (3) are almost identical, and the value

$\beta=24,534 / T_{o}-2.3$,

associated with the low-pressure limit of the reaction-rate coefficient $k_{1}$, is employed for evaluating the nondimensional activation temperature $\beta$ in (11).

Standard mixture-averaged methods [29] were used to compute the thermal conductivity $\lambda$, whereas $D_{\mathrm{H}_{2} \mathrm{O}_{2}}$ was evaluated in terms of binary diffusion coefficients with use made of (6). The resulting approximate expressions

$\lambda=1.943 \times 10^{-3} T_{o}^{0.7} \mathrm{~J} /(\mathrm{m} \mathrm{s} \mathrm{K})$

and

$D_{\mathrm{H}_{2} \mathrm{O}_{2}}=2.53 \times 10^{-9} T_{o}^{1.7} / p \quad \mathrm{~m}^{2} / \mathrm{s}$

were seen to provide sufficient accuracy in the range of conditions pertaining to Fig. 1, with $T_{o}$ in $\mathrm{K}$ and $p$ in atm, respectively. With use made of (12)-(20) together with $C_{\mathrm{H}_{2}}=X_{\mathrm{H}_{2}} p /\left(R^{\circ} T_{0}\right)$ and the values $h_{\mathrm{H}_{2} \mathrm{O}}=-241,845 \mathrm{~J} / \mathrm{mol}$ and $R^{o}=8.314 \mathrm{~J} /(\mathrm{mol} \mathrm{K})$, Eq. (11) finally becomes

$$
\begin{aligned}
a= & \left(\frac{5.45 \times 10^{-12} T_{o}^{2.0966} e^{11,291 / T_{o}}}{p X_{\mathrm{H}_{2}}^{1 / 3}\left(1+1.5 X_{\mathrm{H}_{2}}\right)^{1 / 3}}\right) \\
& \times\left(\frac{1+1.88 \times 10^{-3} e^{6265 / T_{o}}}{24,534 / T_{o}-2.3}\right)^{1 / 6} \\
& \times\left(\frac{1+7.76 \times 10^{10} T_{o}^{-4.2} p\left(1+1.5 X_{\mathrm{H}_{2}}\right)}{0.42^{\left\{1+\left[0.814 \log \left(7.76 \times 10^{10} T_{o}^{-4.2} p\left(1+1.5 X_{\mathrm{H}_{2}}\right)\right]^{2}\right\}^{-1}\right.}}\right)^{1 / 3}
\end{aligned}
$$

with $a$ in $\mathrm{cm}, T_{o}$ in $\mathrm{K}$, and $p$ in atm.

\section{The classical explosion diagram}

For given values of $T_{o}, p$, and $X_{\mathrm{H}_{2}}$, the critical vessel radius can be computed by direct evaluation of (21). Alternatively, for given 
values of $a$ and $X_{\mathrm{H}_{2}}$, Eq. (21) can be used to determine the pressure as a function of the temperature. The equation can be solved explicitly for $p$ when the conditions of temperature and pressure are such that the dissociation reaction $\mathrm{H}_{2} \mathrm{O}_{2}+\mathrm{M} \stackrel{1}{\rightarrow} 2 \mathrm{OH}+\mathrm{M}$ is either in the low-pressure limit or in the high-pressure limit, corresponding respectively to values of the coefficient ratio $x=k_{0} C_{\mathrm{M}_{1}} / k_{\infty}$ much smaller and much larger than unity. The corresponding limiting solutions, obtained by replacing the last factor in (21) by unity in the low-pressure limit and by $x^{1 / 3}$ in the high-pressure limit, with $x$ given in (15), can be expressed in compact form by introducing an exponential to represent approximately the temperature dependence in the resulting equations. The expressions

$p=\frac{1.69 \times 10^{-5} e^{10,330 / T_{o}}}{a X_{\mathrm{H}_{2}}^{1 / 3}\left(1+1.5 X_{\mathrm{H}_{2}}\right)^{1 / 3}} \quad$ for $x \ll 1$

and

$p=\frac{1.90 \times 10^{-9} e^{17,175 / T_{0}}}{a^{3 / 2} X_{\mathrm{H}_{2}}^{1 / 2}}$ for $x \gg 1$

are obtained when the value of the temperature exponent is selected to fit results in the range $700 \mathrm{~K}<T_{o}<900 \mathrm{~K}$.

As mentioned earlier, for the conditions of Fig. 1, the reaction $\mathrm{H}_{2} \mathrm{O}_{2}+\mathrm{M} \stackrel{1}{\rightarrow} 2 \mathrm{OH}+\mathrm{M}$ is in the intermediate fall-off regime with $x \sim O(1)$, so that the determination of $p$ requires in principle the solution of the implicit Eq. (21). Results obtained for $a=3.7 \mathrm{~cm}$ and $X_{\mathrm{H}_{2}}=0.66$ are shown as a solid curve in Fig. 1. For completeness, the figure also includes as dotted curves the limiting solutions (22) and (23), the dotted curve having the steeper slope clearly corresponding to (23). The pressure obtained by solving (21) is seen to approach the value (22) at low pressure and the value (23) at high pressure, as it should, but, as expected, the errors involved in using either of these simplified expressions are significant. It is curious that when falloff is included the predicted pressures in Fig. 1 lie above the predictions for both limiting cases. Also, it is notable how closely the solid curve osculates the experimental upper limit in Fig. 1.

\section{Discussion of complicating factors and uncertainties}

It is worthwhile to recall that experimentally the measured third limit depends on the thickness of the salt coating on the inner surface of the vessel [8], lighter coatings moving the curve to lower pressures, explained by such coatings not completely converting the significant active species to stable inactive molecules at the wall [3]. For this reason, the results in Fig. 1 pertain only to sufficiently thick wall coatings. It is curious that more detailed numerical computations $[19,30]$ exhibit better agreement with experiment for more lightly coated walls, the difference suggesting deficiencies in the detailed chemistry employed there for the third limit. This underscores the desirability of the further chemicalkinetic investigations indicated at the end of this section.

Away from the upper nose of the explosion diagram in Fig. 1, the temperature dependence of the critical explosion pressure is seen to be predicted remarkably well by the analytical expression (21). This agreement in slope is determined largely by the activation temperatures present in (14) and (17). The predicted slight curvature is of the opposite sign from that shown in the experimental curve, but Lewis and von Elbe [3] indicate that the experimental measurements are partly extrapolated to higher pressures, and therefore it is possible that more accurate measurements would have revealed a change in the sign of the curvature. Larger departures from the experimental data are observed as crossover is approached near the turning point, where the competition of $\mathrm{H}+\mathrm{O}_{2} \rightarrow \mathrm{OH}+\mathrm{O}$ with $\mathrm{H}+\mathrm{O}_{2}+\mathrm{M} \rightarrow \mathrm{HO}_{2}+\mathrm{M}$ becomes significant, eventually leading to the transition to the second explosion limit, an effect not described by the two-step reduced description used here.

The present analysis also neglects the heat release associated with the overall reaction $\mathrm{H}_{2}+\mathrm{O}_{2} \stackrel{\text { II }}{\rightarrow} \mathrm{H}_{2} \mathrm{O}_{2}$, the effect of which was verified by additional numerical computations to shift downwards the resulting pressure curve by about $100 \mathrm{mmHg}$, a hardly noticeable change in the logarithmic scale employed in the diagram. Although effects of $\mathrm{H}$-atom consumption through $\mathrm{H}+\mathrm{O}_{2} \rightarrow \mathrm{OH}+\mathrm{O}$ and of heat release by $\mathrm{H}_{2} \mathrm{O}_{2}$ production could be incorporated into the description, following our previous study of homogeneous ignition [12], to focus more directly on the essential mechanism controlling the third explosion limit, we purposely prefer to leave them aside in the present study, since the substantial increase in complexity that would result does not seem to us to be warranted.

The quasi-steady weakly reactive state described in our FrankKamenetskii analysis necessarily would be preceded in experiments by a short transient stage, not considered here, that starts immediately following the admittance of the reactants into the vessel. The formulation given in (9) relies on the assumption that the consumption of reactants during the transient process leading to the establishment of the weakly reactive solution is negligibly small. The accuracy of this assumption can be investigated by noting that, since the production of one molecule of hydrogen peroxide involves the consumption of one molecule of hydrogen according to the overall reaction $\mathrm{H}_{2}+\mathrm{O}_{2} \stackrel{\mathrm{II}}{\rightarrow} \mathrm{H}_{2} \mathrm{O}_{2}$, the relative deviation of the $\mathrm{H}_{2}$ concentration from its initial value can be expected to be of order $C_{\mathrm{H}_{2} \mathrm{O}_{2 c}} / C_{\mathrm{H}_{2}}$, where $C_{\mathrm{H}_{2} \mathrm{O}_{2 c}}$ is the characteristic $\mathrm{H}_{2} \mathrm{O}_{2}$ concentration of the weakly reactive solution, defined in (8). The evaluation of $C_{\mathrm{H}_{2} \mathrm{O}_{2 c}} / C_{\mathrm{H}_{2}}$ with use made of (8), (12)-(15), (18), and (19) indicates that the hydrogen consumption associated with the initial transient production of $\mathrm{H}_{2} \mathrm{O}_{2}$ is in fact negligibly small (e.g., $C_{\mathrm{H}_{2} \mathrm{O}_{2}} / C_{\mathrm{H}_{2}} \sim 10^{-3}$ for $T_{o}=800 \mathrm{~K}$ and $p=1$ ). Hydrogen consumption during the transient process actually would be somewhat larger than this because hydrogen would also react according to the overall reaction $2 \mathrm{H}_{2}+\mathrm{O}_{2} \stackrel{\mathrm{I}}{\rightarrow} 2 \mathrm{H}_{2} \mathrm{O}$ to produce water vapor, but, from similar estimates, the percent deviation of $\mathrm{C}_{\mathrm{H}_{2}}$ from its initial value is still expected to remain always below $1 \%$ for the conditions of interest in Fig. 1, so that the associated reactant-consumption corrections to the result (21) would be negligibly small.

In writing (9), molecular diffusion is assumed to be the dominant transport mechanism for heat and mass, that being the assumption underlying previous theoretical analyses of ignition in closed vessels [3]. As already recognized in early work [5], however, convection can be expected to be significant in the transient stage following the injection of the reactant into the vessel and may also be nonnegligible in the quasisteady stage, as a result of the emergence of buoyancy-induced velocities of order $\sqrt{g a(\delta \rho / \rho)}$, where $g$ is the gravitational acceleration and $\delta \rho / \rho$ is the relative density variation in the vessel. Density differences are induced in the weakly reactive flow field by the small differences of temperature and mean molecular weight associated with the chemical reactions. For the problem at hand, the exothermic chemical reactions increase the temperature, thereby decreasing the density, but also simultaneously increase the density by increasing the local molecular weight, because both overall reactions I and II reduce the number of moles in the system. As a consequence of these counteracting effects, the resulting density differences in the weakly reactive solution are expected to be quite small at the third explosion limit.

An estimated upper bound to the buoyancy-induced velocity can be obtained by neglecting molecular-weight variations in assuming $\delta \rho / \rho \sim\left(T_{o}-T\right) / T_{o} \sim \beta^{-1}$ to give $\sqrt{g a / \beta}$ for the induced velocity, thereby yielding $\sqrt{g a^{3} / \beta} / D_{\mathrm{H}_{2} \mathrm{O}_{2}}$ as an upper bound for the representative Peclet number. For the conditions pertaining 
to Fig. 1, this last quantity takes characteristic values that are of the order of a few tens, thereby indicating that the resulting toroidal flow would be laminar and steady. The corresponding weakly reactive analysis, including a buoyancy-induced flow symmetric about the vertical axis, will not be pursued here, but it is noted that the enhanced rate of mass transport emerging in the presence of convection could be incorporated approximately in the diffusionreaction model by considering a larger effective value of $D_{\mathrm{H}_{2} \mathrm{O}_{2}}$ in (10) and (11). The associated increase in the hydrogen-peroxide diffusivity would shift the prediction of the critical pressure in Fig. 1 upwards, following the proportionality rule $p \propto D_{\mathrm{H}_{2} \mathrm{O}_{2}}^{1 / 2}$ inferred from (10). The magnitude of the resulting shift, however, is not expected to be seen to be very large, partly because of the logarithmic scale used in the figure, since the increase in the effective value of $D_{\mathrm{H}_{2} \mathrm{O}_{2}}$ would be at most of order unity for the slow laminar flow envisioned here.

The validity of the reduced mechanism employed here was also tested by performing additional numerical integrations of the steady diffusion-reaction equations with reactant consumption neglected and with the six previously discussed elementary reactions $\mathrm{H}_{2} \mathrm{O}_{2}+\mathrm{M} \stackrel{1}{\rightarrow} 2 \mathrm{OH}+\mathrm{M}, 2 \mathrm{HO}_{2} \stackrel{2}{\rightarrow} \mathrm{H}_{2} \mathrm{O}_{2}+\mathrm{O}_{2}, \mathrm{HO}_{2}+\mathrm{H}_{2} \stackrel{3}{\rightarrow}$ $\mathrm{H}_{2} \mathrm{O}_{2}+\mathrm{H}, \mathrm{H}_{2}+\mathrm{O}_{2} \rightarrow \mathrm{HO}_{2}+\mathrm{H}, \mathrm{OH}+\mathrm{H}_{2} \rightarrow \mathrm{H}_{2} \mathrm{O}+\mathrm{H}$, and $\mathrm{H}+\mathrm{O}_{2}+$ $\mathrm{M} \rightarrow \mathrm{HO}_{2}+\mathrm{M}$ adopted for the chemistry description, the rate coefficients for the last three reactions having been taken from [31]. Besides the energy equation, conservation equations were written in dimensional form for species $\mathrm{H}_{2} \mathrm{O}_{2}, \mathrm{HO}_{2}, \mathrm{H}$, and $\mathrm{OH}$. Multicomponent transport diffusion was employed, resulting in expressions for effective diffusivity coefficients of $\mathrm{HO}_{2}, \mathrm{H}$, and $\mathrm{OH}$ analogous to (6) under these conditions. For a given temperature, the numerical integrations, including a boundedness condition at the center and an isothermal wall with zero radical concentrations, were carried out for increasing values of the pressure, until critical conditions were reached for which the resulting concentrations and temperature were seen to abruptly increase beyond realistic limits, thereby indicating explosion. The results were found to be in excellent agreement with those obtained by evaluating (21), the differences in critical pressures remaining less than $10 \%$ and so not observable in the figure. The errors associated with the introduction of steadystate assumptions for all radicals are therefore comparable with those previously observed in computations of homogeneous ignition times [12].

The specific numerical evaluation of (11) is subject to uncertainties in reaction-rate parameters, mainly in $k_{1}$ and $k_{3}$. Uncertainties in $k_{2}$ can be expected to be less pronounced, since the expression (16) employed here, taken from [23], is based on recent experimental rate measurements for the specific temperature range of interest here, and the value of $k_{2}$ also is less critical, because this rate coefficient enters in (11) only through a square root. Although $k_{1}$ is also taken from a very recent assessment [21], no information is currently available on the chaperon efficiency of $\mathrm{H}_{2}$ relative to that of $\mathrm{O}_{2}$. The value 2.5 , assumed in writing (12), is representative of typical $\mathrm{H}_{2}$ efficiencies in direct recombination reactions, but larger or smaller values are also equally possible, leading, respectively, to a downward or upward shift in the critical pressure level. For instance, introducing an efficiency of 3.5 causes a decrease of pressure of approximately $200 \mathrm{mmHg}$ at $T=500^{\circ} \mathrm{C}$, while an assumed efficiency of 1.5 increases the pressure by about $300 \mathrm{mmHg}$.

As previously mentioned, a large degree of uncertainty is present in the rate coefficient $k_{3}$. An increase in this rate coefficient by a given factor tends to decrease the explosion pressure by an amount of the order of the cube root of that factor, as can be inferred from (11) when account is taken only of the pressure dependences of $D_{\mathrm{H}_{2} \mathrm{O}_{2}}, C_{\mathrm{M}_{1}}$, and $C_{\mathrm{H}_{2}}$ without consideration of falloff effects. For instance, the recommendation of [26] to decrease $k_{3}$ by a factor of 2.1 would result in an increase of the explosion pressure by about
$30 \%$, whereas the suggested increase by $25 \%$, present in [25], would cause a decrease of about $8 \%$ in the predicted explosion pressure. Clearly, these differences, and, to a lesser extent, those pointed out in the preceding paragraph, can be quite significant. These findings strongly indicate that more reliable predictions of hydrogen ignition at the third explosion limit warrant more accurate assessments of $k_{3}$ and of the $\mathrm{H}_{2}$ chaperon efficiency in collisions leading to hydrogen-peroxide dissociation.

\section{Concluding remarks}

It is noteworthy how simple, in principle, is the chemistry of the third explosion limit, dominated by just the two overall steps (I) and (II), with the rates given in Eqs. (2) and (3), the latter expressing the autocatalytic character of step (II), and the main heat release occurring in step (I), the major effective reactant for both steps being hydrogen peroxide. An indication of the progress thereby accomplished, in nearly three quarters of a century of research, can be inferred from the 1941 statement [6] "... the character of the third explosion limit has remained unsettled ... A rigorous quantitative treatment ... is hopelessly difficult." Understanding has finally progressed to a point at which this statement no longer is true. While further improvements in knowledge of values of rate parameters for the key elementary steps $\mathrm{H}_{2} \mathrm{O}_{2}+\mathrm{M} \stackrel{1}{\rightarrow} 2 \mathrm{OH}+\mathrm{M}$ and $\mathrm{HO}_{2}+\mathrm{H}_{2} \stackrel{3}{\rightarrow} \mathrm{H}_{2} \mathrm{O}_{2}+\mathrm{H}$ are warranted in the future for increasing accuracies of predictions, the essential understanding of the key aspects of the chemistry of the third limit now exists.

\section{Acknowledgments}

This work was supported by the US AFOSR Grant \# FA955012-1-0138, by the Comunidad de Madrid through Project \# P2009/ENE-1597, and by the Spanish MCINN through Project \# CSD2010-00011.

\section{References}

[1] C.N. Hinshelwood, A.T. Williamson, The Reaction Between Hydrogen and Oxygen, The Clarendon Press, Oxford, 1934.

[2] N.N. Semenov, Chemical Kinetics and Chain Reactions, The Clarendon Press, Oxford, 1935.

[3] B. Lewis, G. von Elbe, Combustion, Flames, and Explosions of Gases, second ed. Academic Press, New York, 1961

[4] O. Oldenberg, H.S. Sommers Jr., J. Chem. Phys. 7 (1939) 279.

[5] O. Oldenberg, H.S. Sommers Jr., J. Chem. Phys. 9 (1941) 114-117.

[6] H.R. Heiple, B. Lewis, J. Chem. Phys. 9 (1941) 584-590.

[7] G. von Elbe, B. Lewis, J. Am. Chem. Soc. 59 (1937) 656-662.

[8] G. von Elbe, B. Lewis, J. Chem. Phys. 10 (1942) 366-393.

[9] A.H. Willbourn, D. Phil, C.N. Hinshelwood, Proc. R. Soc. London, A 185 (1946) 353-369.

[10] C. Treviño, Ignition phenomena in $\mathrm{H}_{2}-\mathrm{O}_{2}$ mixtures, Prog. Astronaut. Aeronaut. 131 (1991) 19-43.

[11] C. Treviño C, F. Méndez, Combust. Sci. Technol. 78 (1991) 197-216.

[12] P. Boivin, A.L. Sánchez, F.A. Williams, Combust. Flame 159 (2012) 748-752.

[13] E. Fernández-Tarrazo, A.L. Sánchez, F.A. Williams, Combust. Flame 160 (2013) 1981-1989.

[14] P. Boivin, A.L. Sánchez, F.A. Williams, Combust. Flame 160 (2013) 76-82.

[15] X. Wang, C.K. Law, J. Chem. Phys. 138 (2013) 134305.

[16] K. Seshadri, N. Peters, G. Paczko, Combust. Flame 146 (2006) 131-141.

[17] P. Saxena, N. Peters, F.A. Williams, Combust. Flame 149 (2007) 79-90.

[18] Ya.B. Zeldovich, G.I. Barenblatt, V.B. Librovich, G.M. Makhviladze, The Mathematical Theory of Combustion and Explosions, Consultants Bureau, New York, 1985.

[19] U. Maas, J. Warnatz, Combust. Flame 74 (1988) 53-69.

[20] F.A. Williams, Combustion Theory, second ed., Benjamin Cummings, Menlo Park, CA, 1985.

[21] J. Troe, Combust. Flame 158 (2011) 594-601.

[22] H. Hippler, J. Troe J, J. Willner, J. Chem. Phys. 93 (1990) 1755-1760.

[23] Ch. Kappel, K. Luther, J. Troe, Phys. Chem. Chem. Phys. 4 (2002) 4392-4398.

[24] R.B. Baldwin, R.W. Walker, J. Chem. Soc., Faraday Trans. I 75 (1979) 140-154.

[25] M.O. Conaire, H.J. Curran, J.M. Simmie, W.J. Pitz, C.K. Westbrook, Int. J. Chem. Kinet. 36 (2004) 603-622.

[26] D. Lee, S. Hochgreb, Int. J. Chem. Kinet. 30 (1998) 385-406. 
[27] D.L. Baulch, C.T. Bowman, C.J. Cobos, R.A. Cox, Th. Just, J.A. Kerr, D. Stocker, J. Troe, W. Tsang, R.W. Walker, J. Warnatz, J. Phys. Chem. Ref. Data 34 (2005) 757-1397.

[28] W. Tsang, R.F. Hampson, J. Phys. Chem. Ref. Data 15 (1986) 1087-1222.

[29] R.J. Kee, G. Dixon-Lewis, J. Warnatz, M.E. Coltrin, J.A. Miller. A Fortran Computer Code Package for the Evaluation of Gas-Phase, Multicomponent
Transport Properties, Sandia National Laboratories, Albuquerque, NM, 1986. Report SAND 86-8246.

[30] Y. Liu, P. Pei, Int. J. Hydrogen Energy 31 (2006) 639-647.

[31] P. Saxena, F.A. Williams, Combust. Flame 145 (2006) 316-323. <http:// maemail.ucsd.edu/combustion/cermech>. 